\title{
Food and Health Security Challenges among Vulnerable Internally Displaced Persons in Nigeria
}

\author{
Endurance Uzobo ${ }^{1}$ \\ Ruth Ebosetale Akhuetie ${ }^{2}$ \\ Department of Sociology ${ }^{1}$ \\ Niger Delta University \\ Wilberforce Island, Nigeria \\ Department of Sociology and Anthropology ${ }^{2}$ \\ University of Benin, Benin City, Nigeria
}

DOI:10.36108/NJSA/8102/61(0140)

\begin{abstract}
It has been estimated that out of the 33 million internally displaced persons in the world, Nigeria accounts for about 3.3 million, representing 10 percent of the total of IDPs.. This figure is currently on the increase as the spat of violence continues especially in the North East by Boko Haram insurgents, North Central by Fulani herdsmen marauders, and other parts of the country by natural disasters and boundary adjustment related issues. An overwhelming majority of Internally Displaced Persons in Nigeria are said to be women and children. Most reports have indicated that, women and children constitute more than 50 percent of the Internally Displaced Camps formation. Given the increase of women and children who are trapped in the circle of violence, some accompanying challenges are those of food security and adequate health provision. Whereas most studies have focused on the general situations IDPs in the country experience, few studies have explored the food security and health challenges faced by the vulnerable population. It is on this note that this conceptual paper seeks to explore the food security and health challenges faced by vulnerable populations with special focus on women and children. The theoretical framework for this study was anchored on the Human security and Feminist Approach. The study concluded that the food security and health situations especially among women and children IDPs is at a critical point, hence, there is urgent need for intervention by concerned stakeholders.
\end{abstract}

Keywords: Food security, health, women, children, Internally Displaced Persons, human security

\section{Introduction}

One burning issue that has caught the attention of the global community is that of internal displacement resulting from both man-made and natural phenomena. Globally, it has been estimated that the number of people displaced annually by conflict and violence has increased since 2003 (Norwegian Refugee Council, 2016). On the average, global report on internal displacement indicates an average of about 5.2 million persons annually in the past 13 years due to insurgency, political instability and terrorist activities of groups such as ISIS and Boko Haram, particularly in the Middle East and Sub- 
Saharan Africa (Owoaje, Uchendu, Ajayi \& Cadmus, 2016). The Norwegian Refugee Council in 2016 reported that as at December 2015, the global estimate of Internally displaced persons (IDPs) due to conflict was 40.8 million. The report further added that three-quarter of these IDPs reside in ten countries of the world, and five of these are in Sub-Saharan Africa.

In 2005, it was estimated that displacement resulting from natural disasters especially droughts, earthquakes, floods, storms and wildfires has affected about 203.4 million people globally (Kett, 2005). Exactly a decade later, 19.2 million people in 113 countries were estimated to have been displaced by natural disasters (Internal Displacement Monitoring Centre, 2016). Most of these displacements occurred in South and Eastern Asian countries while slightly over a million occurred in Sub-Saharan Africa (Norwegian Refugee Council, 2016).

In Nigeria, the number of internally displaced people is on the increase because of Boko Haram insurgency in the North-east and Fulani Herdsmen attack in North-central Nigeria. Of the total figure of IDPs recorded by International Organization for Migration, Nigeria accounts for about 3.3 million representing 10 per cent of the total of IDPs in the world as at May 2014. Out of this figure, about 13.33 per cent were displaced due to communal clashes, 0.99 per cent by natural disasters and 85.68 per cent because of insurgency attacks by Islamists (International Organization for Migration (International Organization for Migration (IOM), 2016).

Reports have shown that an overwhelming majority of Internally Displaced Persons in Nigeria are women and children while women and girls are severely exposed to risks (United Nations Refugee Agency, 2016; ActionAid, 2016). Adimula (2016) also indicated that, women and children constitute more than 50 percent of the Internally Displaced Camps formation. A major issue surrounding the internally displaced is what are the main challenges that the vulnerable population face? Given the increase of women and children who are trapped in the circle of violence, some accompanying challenges are those of securing food and health. At this point, an important question is what can be done to ameliorate the food and health crises vulnerable IDPs face given the fact that they continue to increase everyday especially in the era of Fulani herdsmen pillaging? It is in a bid to address some of these questions and background that this conceptual paper seeks to undertake a secondary analysis to explore the food security and health challenges faced by vulnerable populations with special focus on women and children. Nevertheless, before proceeding, it is expedient that some concepts are clarified.

\section{Internally Displaced Persons}

The concept of IDPs though does not have a legal definition, is not as elusive as related terms such as refugees, migrants etc. The 1992 report of the Secretary-General of the United Nations is the most widely used definition of IDPs. According to this report (cited in Ayinmoro \& Uzobo, 2016) IDPs are; 'persons who have been forced to flee their homes suddenly or unexpectedly in 
large numbers, as a result of armed conflict, internal strife, systematic violations of human rights or natural or man-made disasters, and who are within the territory of their own country.'

In a similar definition, the African Union Convention for Protection and Assistance of Internally Displaced Persons in Africa (Kampala Convention, 2009), defined the term Internally Displaced Persons as; "persons or groups of persons who have been forced or obliged to flee or to leave their homes or places of habitual residence, in particular as a result of or in order to avoid the effects of armed conflict, situations of generalized violence, violations of human rights or natural or human-made disasters, and who have not crossed an internationally recognized State border'.

Durosaro and Ajiboye (2011) in buttressing the above definitions, stated that there are two major components of the IDPs; the coercive or otherwise involuntary movement which takes place within national borders mainly caused by factors such as armed conflict, violence, human rights violation and disaster. These factors afford people little or no choice at all to leave their homes and further alienate them from the most essential protection mechanisms, such as community networks, access to services and livelihoods. The second component of the IDPs as identified by Durosaro and Ajiboye (2011) is the movement within national borders which IDPs remain legally under the protection of national authorities of their habitual residence, unlike refugees who have been deprived of the protection of their state (country) of origin, they are expected to enjoy the same rights as those who are not displaced.

In any way IDPs are defined, it is worthy to note that they have not crossed internationally recognised boundary. In other words, their movement might just be temporal. This means that they could return whenever the prevailing circumstances (e.g. conflicts, wars, natural disasters) that made them to leave in the first place is no longer in their former place of residence.

\section{Vulnerable Population}

The set of persons or population classified as vulnerable differs from one country to the other and from one profession to another. Based on this, there are several definitions focusing on different segment of populations. Flores and Zydor (2014), adopting a clinical approach, defined vulnerability as; "the state of an individual or population being vulnerable to a particular disease or event". Still from a clinical perspective, they added that, in general, a vulnerable population is a group of people who are disadvantaged in some way. Typically, they have less power than most of their peers and fewer resources to dedicate to their health (Flores \& Zydor, 2014).

Still, Flores and Zydor (2014) using an ethical approach, defined vulnerable population as a group of people who are comparatively (or absolutely) unable to protect their own welfares which might result to them being exposed to maltreatment. The Robert Wood Johnson Foundation (2001) defined vulnerable populations to include the economically deprived, racial 
and ethnic minorities, the uninsured, low-income children, the elderly, the homeless, People living with HIV (PLWH), and those with other chronic health conditions e.g. mental illness. Based on this assertion, vulnerability could be enhanced by race, ethnicity, age, sex, and factors such as economic status, insurance coverage (or lack thereof) etc.

Aday (1991) categorised vulnerable populations into three major groups namely; physical, psychological, and social vulnerabilities. Those with high probability of physical vulnerability include high-risk mothers and infants, the chronically ill and disabled persons, and people living with HIV/AIDS. Viewing vulnerability from a psychological perspective, vulnerability is related to people with some kind of psychological conditions such as; major depression, schizophrenia, bipolar disorder, and attention-deficit/hyperactivity disorder, including those with a history of alcohol/ substance abuse and those with suicidal tendencies. Socially, vulnerable populations could be those living in violent families, the displaced and homeless, immigrants, and refugees (Aday, 1991).

However, for this paper, the concept vulnerable population would be succinctly described to refer to women and children who are relatively or absolutely incapable of protecting their own interests because of several limiting factors such as insufficient power, intelligence, resources, strength, or other needed attributes to secure their basic needs such as food, shelter, health etc. This often leads them to face serious food and health challenges.

\section{Food Security}

Food security is a flexible concept. The definition of the concept changes from time to time. According to Maxwell and Smith (1992) just a decade ago, there were about 200 definitions in published writings. The current definition of food security is one initiated in the process of international consultation leading to the World Food Summit (WFS) in November 1996. A contrasting definition is that of the Food and Agricultural Organisation (FAO) earlier adopted in 1974. A comparison of these definitions brings to light the substantial reconstruction of official thinking on food security over the past 25 years. Let us briefly discuss these definitions.

The World Food Summit organised by FAO in 1974 explained food security thus: "availability at all times of adequate world food supplies of basic foodstuffs to sustain a steady expansion of food consumption and to offset fluctuations in production and prices" (United Nations, 1975). However, in 1983, the FAO extended the concept of food security to include securing access by vulnerable people to accessible supplies of goods and services. Consequently, the FAO shifted its attention of food security to include a balance between the demand and supply side of the food security equation rather than focusing solely on the demand aspect as other definitions have demonstrated. Hence, food security is an inclusive term that guarantees that all people at all times have access to both physical and economic necessities of life such as food and shelter (FAO, 1983). 
The World Bank highly persuasive report titled "Poverty and Hunger" in 1986 focused on the temporal dynamics of food insecurity. It distinguished between chronic food insecurity which is associated with problems of enduring or structural poverty and low economic status, and transitory food insecurity, which involve periods of intensified pressure caused by natural disasters, economic recession or conflict. Thus, the World Bank (1986) elaborated food security to include continued access of all people at all times to sufficient food for an active, healthy life.

Consequently, in the mid-1990s, food security was thus given much significance, straddling a gamut from the individual to the global level. Nevertheless, access is now defined in terms of having sufficient food, signifying continued concern with protein-energy malnutrition. However, this has been expanded to integrate food safety and nutritional balance, revealing concerns about food composition and minor nutrient requirements for an active and healthy life. Hence, preference for food whether socially or nutritionally has now been a serious factor for consideration. Still, the 1996 World Food Summit adopted a more complex definition with reference to the individual, household, national regional and global level thus:

"Food security, at the individual, household, national, regional and global levels [is achieved] when all people, at all times, have physical and economic access to sufficient, safe and nutritious food to meet their dietary needs and food preferences for an active and healthy life". (FAO, 1996)

This definition was again refined in "the State of Food Insecurity" in 2001 to a condition that exists when all people, at all times, have physical, social and economic access to adequate, safe and nutritious food that meets their dietary needs and food preferences to live a healthy and an active life (FAO, 2002).

Basically, we could describe food security as a phenomenon relating to individuals. Its main focus is in relation to nutritional status of the individual household members, and the risk of that adequate status not being achieved or becoming undermined. The latter risk defines the vulnerability of individuals in this situation. The definitions reviewed above imply, vulnerability may occur both as a chronic and transitory condition. In this regard, Clay (2002) stated that:

"Food security exists when all people, at all times, have physical, social and economic access to sufficient, safe and nutritious food which meets their dietary needs and food preferences for an active and healthy life. Household food security is the application of this concept to the family level, with individuals within households as the focus of concern, (while) Food insecurity exists when people do not have adequate physical, social or economic access to food as defined above". 


\section{Health Security}

The concept of health security is currently receiving a wide range of acceptance. However, there are various and incompatible definitions among various scholars. This might be as a result of the orientation of their discipline. Thus, there are inadequate amplifications of the concept of health security in public health operational terms, and insufficient reconciliation of the health security concept. More importantly, there are major differences in understanding and use of the concept in different settings. Policymakers in industrialized countries emphasize protection of their populations especially against external threats, for example terrorism and pandemics; while health workers and policymakers in developing countries and within the United Nations system understand the term in a broader public health context. Indeed, the concept is used inconsistently within the UN agencies themselves, for example the World Health Organization's restrictive use of the term 'global health security' (Aldis, 2008).

In 2001, the World Health Assembly's Resolution 54.14 'Global health security: epidemic alert and response' linked the health security concept to a global strategy for prevention of movement of communicable diseases across national borders. This resolution supported the revision of the International Health Regulations (IHRs) and was the first step in associating 'global health security' with IHR compliance. This was taken forward in 2007, when health security was selected as the theme of the World Health Day and of the annual World Health Report (WHR), titled A Safer Future: Global Public Health Security in the 21st Century (WHO, 2007). Significantly, this report addresses only 'global public health security', which it defined as '. . . the activities required . . . to minimize vulnerability to acute public health events that endanger the collective health of populations living across geographic regions and international boundaries'.

Thus, the 2007 WHR focuses only on 'specific issues that threaten the health of people internationally', with emphasis almost exclusively on global compliance with the revised IHRs, which came into force in June 2007. However, according to Lancet (2007), the WHO is yet to fully address the greater questions on the definition, scope and implementation of 'health security'. Baldwin interrogated this question to include; Security for whom? Security for which values? How much security? Security from what threats? Security by what means?

So far, these debates have done nothing to clarify the definition of 'health security'. A search of the term using an internet search engine confirms an alarming lack of agreement on the meaning and scope of the concept. Internet search on the concept often finds citations to bio-terrorism or trans-border spread of disease, effects of rising health care costs and health insurance in developed countries, HIV/AIDS, and unrelated matters (e.g. electronic home protection systems). Only a few referred to 'health security' in the sense intended by the UNDP which is on a global scale. 
Nevertheless, for the purpose of this paper we shall define Health Security as those conditions that aim to guarantee a minimum protection from diseases and unhealthy lifestyles of an individual, group of persons or a community. The United Nations revealed that in both less developed and developed countries, threats to health security are usually higher among the poor people in rural areas, especially women and children. This they attributed to the shortage of health services and facilities, clean water and other basic necessities including malnutrition.

\section{Theoretical Framework}

For this paper, the Human Security Approach and the Feminist Theory were adopted. While the human security approach addresses the human security needs that IDPs might face and how it should be addressed, the feminist theory looks at the vulnerability of women in internal displacement situations.

\section{Human Security Approach}

The emergence of the human security approach in the discussion of developmental needs of IDPs was the product of a convergence of various complex factors. This approach therefore challenges the traditional dominance of state-centric paradigm of security. The Human security approach is an emerging paradigm for understanding global vulnerabilities whose proponents challenge the traditional notion of national security by arguing that the proper referent for security should be the individual rather than the state. In other words, the primary role of the state should be to ensure the human security needs of the individuals such as; food security, health security, political security, environmental security etc.

There are two major schools of thought that attempted to illuminate the best practice that could guarantee human security especially for vulnerable populations such as women and children. They include the "Freedom from Fear Approach" as well as the "'Freedom from Want Approach." Of these two approaches, the freedom from want best addresses the concerns of this study. The core of these approaches is clearly on what threat individuals should be protected from and over the appropriate mechanisms for responding to these threats. The Freedom from fear approach confines its application to the practice of Human Security to shielding people from violent conflicts while recognising the fact that these violent threats are intricately related to poverty, lack of state capacity and other forms of inequalities. Hence, this approach opines that restricting the focus of human security to violence is an accurate and controllable approach towards human security. This approach went ahead to add that emergency assistance, conflict prevention and resolution, peacebuilding are preconditions to human security. The freedom from want approach on its own part, advocates for all-inclusiveness in the quest to achieving human security globally. It argues that the threat to human security should be elaborated to include hunger, disease and natural disasters because they are interrelated and inseparable concepts in addressing the source of human 
insecurities (UNDP, 1994), and that they kill far more people than war, genocide and terrorism combined (Tadjbakhsh, 2007). In essence, the freedom from want approach differs from the "Freedom from Fear", as it expands its focus beyond violence with emphasis on development and security goals.

\section{Feminist Theories}

Feminist theories often focus on understanding the peculiar problems women face in relation to men because of an unequal access to the socio-political and economic necessities in life. Gender and development theories have been developed for the attainment of the international development goals. The first gender theory to be developed in relation to women IDPs and refugees was the Harvard Framework, from which the People-Oriented-Planning (POP) method emerged. The Harvard Framework highlights the importance of investigating issues like, who does what, who owns what, and who is in control of what within the community. Then the Moser Method which is another valuable framework break gender-specific needs according to planned people's interests. The Moser Method pays attention to gender planning and training as a means of meeting the special needs of women (Moser, 1993). Still, Women's Equality and Empowerment Framework (WEEF) objectives, is helping planners to question the existing women empowerment practices and interventions and how they support development of the vulnerable (especially women) [UNDP, 2001]. United Nations International Children's Emergency Fund (UNICEF) pays more attention to the empowerment of women to overcome inequity when providing humanitarian aid and resources. Therefore, the POP framework for analysis is preferred when working with internally displaced women (UNDP, 2001).

The People-Oriented Planning (POP) Approach is a version of the Harvard Analytical Framework used in refugee circumstances. It is a training tool initiated by Mary Anderson and Catherine Overholt for the United Nations High Commissioner for Refugees (UNHCR) developed for gender planning in refugee and IDPs situations. POP was developed to support refugee workers in improving involvement and access to programmes by providing an outline for investigating the socio-cultural and economic issues that affect refugees and internally displaced people. POP was first initiated in 1992 and is being currently used by several developmental agencies e.g. UNHCR to train all their staff in its refugee situations or similar situations. POP model stresses that relief workers must examine the social and economic roles of all people especially that of men and women (UNDP, 2001). In doing this, three elements are emphasized namely: change, participation, and the importance of analysis. The framework emphasizes the effects of change that the displaced people experience during armed conflict. Involvement of people affected by displacement determines the success of relief aid operations which must include both women and men. The theories examine associations between poverty, gender equality, human rights, reproductive health, conflict and 
violence against vulnerable people especially women and teenage girls (UNDP, 2002).

The Fourth World Conference on Women, held in Beijing in 1995, called for more effective protection and assistance for displaced women. The Representative of the UN Secretary-General on IDPs was asked by the Commission on Human Rights to pay attention to the needs of internally displaced women. Currently, there has arisen more attention not only to the problem of internal displacement, with a higher focus on the situations of internally displaced women. Using the challenges faced by internally displaced people, the UN agencies have focused more on the problems faced by internally displaced women more seriously and systematically than that of men. Hence, it is imperative to pay special attention to diverse ways in which gender influences internal displacement and development. Most NGOs have come to realize the significance of using a gender perspective to internal displacement while the predicament faced by women continues to be viewed through various gender perspectives for the development of policies, guidelines and training programmes. A study by UNICEF confirmed that IDPs still experience serious problems of insecurity, lack of shelter, food shortages and landlessness (UNICEF, 1998).

\section{Application of the Theories to the Study}

In applying the human security approach to the challenges facing IDPs in Nigeria using the freedom from want approach, it is clear that the issue of security goes beyond providing a safe haven for the displaced and protection from external threats. Rather, it involves ensuring the satisfaction of their basic needs, especially the need for food, and safeguarding them against diseases and epidemic outbreaks which can destroy territories faster than conflict itself. The feminist theory on the other hand offers a gender relations framework to humanitarian assistance, one which requires basic understanding and acceptance of the principles upon which all gender theory rests. It explains the position of women in socio-economic development and their disadvantaged position in periods of conflict and violence. According to this theory, Women, especially in developing countries, bargain their lives within the arrangement framed by their cultural environment. The theory states that when lives change significantly, as in the case of forced migration, women often lose their negotiated positions and return to less equitable social life (UNDP, 2002). Thus, while the feminist theory targets the identified vulnerable population, the human security approach delineates the need(s) to be addressed.

\section{Methodology}

This study investigates the humanitarian crises existing among women and children especially with regards to food and health. Data for this study were mainly gathered through secondary sources. Hence, most of the statistics in this study were collected from international and national NGOs and governmental agencies such as; Food and Agriculture Organization of the United Nations 
(2016), United Nations Office for the Coordination of Humanitarian Affairs (2016) and other secondary published and unpublished sources. The study primarily focused on the North-eastern part of the country, especially Adamawa, Borno and Yobe states, being the three major states with the highest number of IDP camps in Nigeria. Thus, in studying the challenges facing vulnerable IDPS in Nigeria, the prevalent situation in the host communities was identified.

From the foregoing, it should be noted that this study has some limitations. First, since the study is based on secondary data, the findings cannot be compared to empirical findings. Hence, this study only gives a general overview of the situation. On this note, there is the need to actually conduct empirical studies to really ascertain the true nature of the problem under discourse. Second, given the statistical reports of various findings, the exact figure of internal displaced persons especially women and children cannot be ascertained as various sources give different figures.

\section{Discussion and Findings}

\section{Food Security Challenges in Crisis Prone Areas in Nigeria}

In order to effectively determine the food security challenges faced by vulnerable IDPs, it is necessary to examine the prevailing situation in insecure zones in Nigeria. The Food and Agriculture Organization of the United Nations report (2016) will be used to describe the food security challenges among vulnerable IDPs using the Cadre Harmonise $(\mathrm{CH})$. In terms of hazard and vulnerability, the report revealed that the sixteen states assessed are affected by various hazards and vulnerability, especially the insurgency that has displaced more than two million persons across several states. Currently there are over 2million, 122,000 and 123,000 internally displaced persons (IDPs) in Borno, Adamawa and Yobe states respectively. Similarly, it also been reported that there are over 41,000, 32,000, 29,000 and 10,000 IDPs in Gombe, Taraba, Kaduna and Plateau states respectively. Though the conflict has declined in Adamawa, Borno and Yobe states and some of the IDPs have started returning to their communities, displacement continues in some affected areas in the North East. The insecurity and displacement have led to low market functioning, reduced land cultivation and destruction of infrastructure such as water pipelines, bridges, health centres, schools, roads, and other social amenities.

The assessment of food availability revealed that staple food and cash crops production was above average in some states such as Jigawa, Kano, Katsina, Kebbi and Sokoto states, while some states like Borno, Plateau and Yobe states experienced below average production. Also, regarding food access, the prices of staple food crops across the states were extremely high compared to the five-year averages (with margins of $100 \%-200 \%$ increase); this is due to inflationary pressure in the economy. Finally, for food utilization including water, access to potable water remained limited across the 16 states and worse in the conflict affected states. Acute malnutrition prevalence rates 
loomed at critical levels in Borno, Katsina, Kebbi, Sokoto and Zamfara states.

With the aid of the Cadre Harmonise $(\mathrm{CH})$ regional framework, insecure populations prone to food crisis in sixteen northern states in Nigeria were identified using food and security outcome indicators. With regards to food utilization, Table 1 identifies food security zones, Table 2 and 3 provide estimates of the population in terms of food and nutrition insecurity in 2016 and projected estimates for 2017. As regards issues of food insecurity, in each of the tables presented below, Phase $1(\mathrm{Ph} \mathrm{1})$ represents zones in the minimal phase of food insecurity, Phase $2(\mathrm{Ph} 2)$ represents zones under pressure, Phase $3(\mathrm{Ph} \mathrm{3})$ represents zones in crisis, Phase $4(\mathrm{Ph} \mathrm{4})$ represents zones in emergency situations while Phase 5 ( $\mathrm{Ph} \mathrm{5)}$ represents zones experiencing famine.

Table 1: Identification of food insecurity zones for the current and projected situation

\begin{tabular}{|l|c|c|c|c|c|c|c|c|c|c|c|c|}
\hline \multicolumn{10}{|l|}{ October - December 2016 } & \multicolumn{1}{|l|}{ lune - August 2017 } \\
\hline State & Total & Ph1 & Ph2 & Ph3 & Ph4 & Ph5 & Total & Ph1 & Ph2 & Ph3 & Ph4 & Ph5 \\
\hline ADAMAWA & 5 & 1 & 1 & 3 & 0 & 0 & 5 & 2 & 0 & 3 & 0 & 0 \\
\hline BAUCHI & 3 & 3 & 0 & 0 & 0 & 0 & 3 & 0 & 3 & 0 & 0 & 0 \\
\hline BENUE & 3 & 3 & 0 & 0 & 0 & 0 & 3 & 1 & 2 & 0 & 0 & 0 \\
\hline BORNO & 3 & 0 & 0 & 1 & 2 & 0 & 3 & 0 & 0 & 1 & 2 & 0 \\
\hline GOMBE & 3 & 3 & 0 & 0 & 0 & 0 & 3 & 2 & 1 & 0 & 0 & 0 \\
\hline JIGAWA & 3 & 1 & 2 & 0 & 0 & 0 & 3 & 0 & 3 & 0 & 0 & 0 \\
\hline KADUNA & 3 & 2 & 1 & 0 & 0 & 0 & 3 & 1 & 2 & 0 & 0 & 0 \\
\hline KANO & 3 & 2 & 1 & 0 & 0 & 0 & 3 & 1 & 2 & 0 & 0 & 0 \\
\hline KATSINA & 3 & 1 & 2 & 0 & 0 & 0 & 3 & 0 & 3 & 0 & 0 & 0 \\
\hline KEBBI & 3 & 0 & 3 & 0 & 0 & 0 & 3 & 0 & 0 & 3 & 0 & 0 \\
\hline NIGER & 3 & 3 & 0 & 0 & 0 & 0 & 3 & 1 & 2 & 0 & 0 & 0 \\
\hline PLATEAU & 3 & 2 & 1 & 0 & 0 & 0 & 3 & 2 & 0 & 1 & 0 & 0 \\
\hline SOKOTO & 3 & 1 & 2 & 0 & 0 & 0 & 3 & 1 & 2 & 0 & 0 & 0 \\
\hline TARABA & 3 & 3 & 0 & 0 & 0 & 0 & 3 & 0 & 3 & 0 & 0 & 0 \\
\hline YOBE & 3 & 0 & 1 & 1 & 1 & 0 & 3 & 0 & 0 & 2 & 1 & 0 \\
\hline ZAMFARA & 3 & 1 & 2 & 0 & 0 & 0 & 3 & 0 & 3 & 0 & 0 & 0 \\
\hline TOTAL & $\mathbf{5 0}$ & $\mathbf{2 6}$ & $\mathbf{1 6}$ & $\mathbf{5}$ & $\mathbf{3}$ & $\mathbf{0}$ & $\mathbf{5 0}$ & $\mathbf{1 1}$ & $\mathbf{2 6}$ & $\mathbf{1 0}$ & $\mathbf{3}$ & $\mathbf{0}$ \\
\hline
\end{tabular}

Source: Food and Agriculture Organization of the United Nations (2016) Cadre Harmonisé for identifying Risk Areas and Vulnerable Populations in Sixteen (16) States of Nigeria

Table 1 shows the Cadre Harmonisé analysis conducted at the zonal level, in the 3 senatorial zones in each of the 16 states. 
Table 2: Estimation of population per phase of food and nutrition insecurity in the current situation -October to December 2016

\begin{tabular}{|c|c|c|c|c|c|c|c|}
\hline 2nd & & \multicolumn{6}{|c|}{ CURRENT SITUATION: OCTOBER - DECEMBER 2016} \\
\hline Administrative & & \multirow[b]{2}{*}{ Total population } & \multirow[b]{2}{*}{ Total population } & Total & Total & Total & Total \\
\hline \multirow[b]{2}{*}{ level } & Total population & & & \multirow[b]{2}{*}{ population } & \multirow[b]{2}{*}{ population } & \multirow[b]{2}{*}{ population } & \multirow[b]{2}{*}{ population in } \\
\hline & & \multirow[b]{2}{*}{ in Phase 1} & \multirow{3}{*}{ in Phase 2} & & & & \\
\hline & & & & \multirow[b]{2}{*}{ in Phase 3} & \multirow[b]{2}{*}{ in Phase 4} & \multirow[b]{2}{*}{ in Phase 5} & \multirow[b]{2}{*}{ Phase 3 to 5} \\
\hline STATE & & & & & & & \\
\hline ADAMAWA & 4196999 & 3041614 & 897958 & 251612 & 5815 & - & 257427 \\
\hline BAUCHI & 6593116 & 5770458 & 605327 & 217331 & - & - & 217331 \\
\hline BENUE & 5247397 & 4616853 & 497726 & 132818 & - & - & 132818 \\
\hline BORNO & 5511759 & 937924 & 1307498 & 1,823462 & 1387862 & 55013 & 3,266337 \\
\hline GOMBE & 3227471 & 2773688 & 453783 & - & - & - & - \\
\hline JIGAWA & 5782600 & 4523822 & 1080211 & 178567 & - & - & 178567 \\
\hline KADUNA & 8263574 & 6652155 & 1399072 & 212348 & - & - & 212348 \\
\hline KANO & 14828136 & 11926278 & 2586081 & 315777 & - & - & 315777 \\
\hline KATSINA & 7558000 & 5143292 & 1712540 & 702168 & - & - & 702168 \\
\hline KEBBI & 4629880 & 1214028 & 2579878 & 835974 & - & - & 835974 \\
\hline NIGER & 5714988 & 4703143 & 916258 & 95588 & - & - & 95588 \\
\hline PLATEAU & 4146442 & 2941118 & 1025700 & 167561 & 12063 & - & 179624 \\
\hline SOKOTO & 5218629 & 3803124 & 1097164 & 318341 & - & - & 318341 \\
\hline TARABA & 3142715 & 2710939 & 368284 & 63492 & - & - & 63492 \\
\hline YOBE & 3280832 & 1169408 & 962350 & 725465 & 423609 & - & 1149074 \\
\hline ZAMFARA & 4626716 & 3398279 & 1072226 & 156211 & - & - & 156211 \\
\hline TOTAL & 91969254 & 65326124 & 18562054 & 6196715 & 1829349 & 55013 & 8081077 \\
\hline
\end{tabular}

Source: Food and Agriculture Organization of the United Nations (2016) Cadre Harmonisé for identifying Risk Areas and Vulnerable Populations in Sixteen (16) States of Nigeria

In Table two, the analysis conducted in 2016 revealed that there was one zone (Borno) classified in phase 5 (famine) and 4 zones (Adamawa, Borno, Plateau and Yobe) in phase 4 (emergency).

\begin{tabular}{|c|c|c|c|c|c|c|c|}
\hline \multirow{2}{*}{$\begin{array}{c}\text { 2nd } \\
\text { administrative } \\
\text { Level } \\
\text { STATE } \\
\end{array}$} & \multirow[b]{2}{*}{$\begin{array}{c}\text { Total } \\
\text { populatioı }\end{array}$} & \multicolumn{6}{|c|}{ PROJECTED SITUATION: JUNE - AUGUST 2017} \\
\hline & & \begin{tabular}{|c} 
Total \\
population \\
in Phase 1 \\
\end{tabular} & $\begin{array}{c}\text { Total population } \\
\text { in Phase } 2\end{array}$ & $\begin{array}{c}\text { Total } \\
\text { population } \\
\text { In Phase } 3 \\
\end{array}$ & $\begin{array}{c}\text { Total } \\
\text { Population } \\
\text { In Phase } 4 \\
\end{array}$ & $\begin{array}{c}\text { Total } \\
\text { Population } \\
\text { in Phase } 5\end{array}$ & $\begin{array}{c}\text { Total } \\
\text { population in } \\
\text { Phase } 3 \text { to } 5 \\
\end{array}$ \\
\hline ADAMAWA & 4196999 & 3172190 & 820060 & 202904 & 1845 & - & 204749 \\
\hline BAUCHI & 6593116 & 5075819 & 1051984 & 465314 & - & - & 465314 \\
\hline BENUE & 5247397 & 4025212 & 819062 & 403124 & - & - & 403124 \\
\hline BORNO & 5511759 & 706278 & 1164184 & 2021909 & 1503677 & 115711 & 3641297 \\
\hline GOMBE & 3227471 & 2642652 & 576692 & 8127 & - & - & 8127 \\
\hline JIGAWA & 5782600 & 4307351 & 1195360 & 279888 & - & - & 279888 \\
\hline KADUNA & 8263574 & 6261093 & 1676986 & 325496 & - & - & 325496 \\
\hline KANO & 14828136 & 11260345 & 3103732 & 464059 & - & - & 464059 \\
\hline KATSINA & 7558000 & 4208619 & 2217149 & 1132233 & - & - & 1132233 \\
\hline KEBBI & 4629880 & 648741 & 2864777 & 1084838 & 31525 & - & 1116362 \\
\hline NIGER & 5714988 & 4476065 & 1104898 & 134026 & - & - & 134026 \\
\hline PLATEAU & 4146442 & 2554558 & 1250168 & 317591 & 24126 & - & 341716 \\
\hline SOKОTO & 5218629 & 3143092 & 1526955 & 548582 & - & - & 548582 \\
\hline TARABA & 3142715 & 2270959 & 651128 & 220628 & - & - & 220628 \\
\hline YOBE & 3280832 & 734954 & 1273173 & 801458 & 465668 & 5579 & 1272705 \\
\hline ZAMFARA & 4626716 & 2712274 & 1585395 & 329047 & - & - & 329047 \\
\hline TOTAL & 91969254 & 58200200 & 22881702 & 8739221 & 2026840 & 121290 & 10887352 \\
\hline
\end{tabular}

Table 3: Estimation of population per phase of food and nutrition insecurity in the projected situation -June to August, 2017 
Source: Food and Agriculture Organization of the United Nations (2016) Cadre Harmonisé for identifying Risk Areas and Vulnerable Populations in Sixteen (16) States of Nigeria

In the projected situation, the zones in Phase 5 will increase from 1 zone to 2 zones (Borno and Yobe) between October - December, 2016 and June- August 2017.

\section{Food Security and Nutrition Challenges among Vulnerable Internally Displaced Persons in Nigeria}

The incessant conflict activities spearheaded by the terrorist group, Boko Haram, continues to limit agricultural and market activities in North-eastern Nigeria, thereby reducing affected resident and displaced populations' access to traditional food and income sources as noted in the FEWS NET reports. IDPs are employing a variety of negative coping mechanisms, including eating fewer or smaller meals, selling assets, and taking loans for food. With the increasing numbers of vulnerable households in Adamawa, Borno, and Yobe, an estimated 4.6 million Nigerians are currently at risk of food insecurity, with at least 3 million people projected to require emergency food assistance between July and September, according to the UN.

A March FEWS NET assessment found that the region's major trade routes are severely restricted, with only one partially functioning route-the road between Maiduguri and Yobe's capital town of Damaturu. In addition, most pastoralists have sold their animals and left the area, losing their household assets and significantly reducing livestock trade. As a result, staple food prices in North-eastern markets are up to 30 percent higher than in neighbouring regions.

Displacement, coupled with limited food availability and limited humanitarian access, has exacerbated North-eastern Nigeria's chronically high levels of acute malnutrition. March/April nutrition surveillance by international NGOs in greater Maiduguri, Borno, found global acute malnutrition rates of at least 30 percent, exceeding the UN World Health Organization's emergency threshold of 15 percent. Between January and April, approximately 16,000 children under the age of five in Adamawa, Borno, and Yobe received treatment for malnutrition as reported by UNICEF. Nutrition and health organizations treated and discharged more than 10,300 recovered children, or 65 percent of those admitted, from therapeutic care. In addition, approximately 32 percent of children in Adamawa, Borno, and Yobe IDP camps require treatment for severe acute malnutrition (SAM), according to the UN. From January to mid-May, nutrition actors admitted more than 1,500 children in camps for SAM treatment. UNICEF and NGO partners are also delivering critical information regarding nutrition and infant and young child feeding to IDPs and host communities.

Report has it that the USAID/FFP has provided over $\$ 13.3$ million to help curb the burning food needs of approximately 100,800 displaced persons and 
host community members in Adamawa, Gombe, and Yobe states. USAID/FFP has also provided cash transfers and food vouchers to IDPs who have lost their livelihoods to enable them to purchase nutritious food from local markets. This assistance aims to increase household purchasing power, improve dietary diversity through increased access to food, prevent malnutrition, and support market activity. In addition, USAID/FFP is supporting nutritional awareness trainings on breastfeeding, dietary diversity, and infant and young child feeding.

For a period of time, farmers were unable to return to the land for the planting season because of the conflict. The harvest cannot therefore meet the needs of millions of people. The fear of improvised explosive devices also discourages farmers from returning. The study revealed that the main drivers of food insecurities in the region is conflict and displacement. Food, it stated is currently the single greatest need for vulnerable IDP populations in camps, informal settlements and host communities. In January to October 2016, about 880,700 people received food assistance either in kind or through cash-based transfers. Limited access and security restrictions are the key operational constraints faced by humanitarian organizations on the ground.

Table 4: Food security and nutrition challenges in among Vulnerable IDPs in Nigeria

\begin{tabular}{|c|c|}
\hline \multirow[t]{3}{*}{$\begin{array}{l}\text { FOOD } \\
\text { SECURITY }\end{array}$} & $\begin{array}{l}\text { Needs: } \\
\text { - An estimated } 5.1 \text { million people are food insecure in Adamawa, } \\
\text { Borno and Yobe States. This includes the IDPs in the states. } \\
\text { - } 66 \% \text { of IDPs report food as their most unmet need. } \\
\text { Thousands of households need better access to seeds, tools, } \\
\text { poultry restocking and other agricultural production inputs. }\end{array}$ \\
\hline & $\begin{array}{l}\text { Response: } \\
\text { - Massive scale-up of food assistance. } \\
\text { - From January to October } 2016 \text {, about } 880,700 \text { people received } \\
\text { food assistance either in kind or through cash-based transfers; } \\
105,127 \text { received inputs for the production of crops and } \\
\text { livestock; } 83,102 \text { people received other forms of livelihood } \\
\text { support. }\end{array}$ \\
\hline & $\begin{array}{l}\text { Gaps \& Constraints: } \\
\text { - Security, access, unavailability of escorts, lack of fuel for } \\
\text { military escorts and helicopters are among the main constraints. } \\
\text { - Limited funding for planned interventions: } \$ 88 \text { million is } \\
\text { required for the most urgent needs. } \\
\text { - Limited national and local capacity for sustainable } \\
\text { interventions. } \\
\text { Insufficient knowledge of the situation of people in the remote, } \\
\text { hard-to-reach areas in Adamawa State. }\end{array}$ \\
\hline NUTRITION & $\begin{array}{l}\text { Needs: } \\
\text { - 398,188: Estimated number of children with severe acute } \\
\text { malnutrition (SAM) in need of nutrition assistance in IDP }\end{array}$ \\
\hline
\end{tabular}




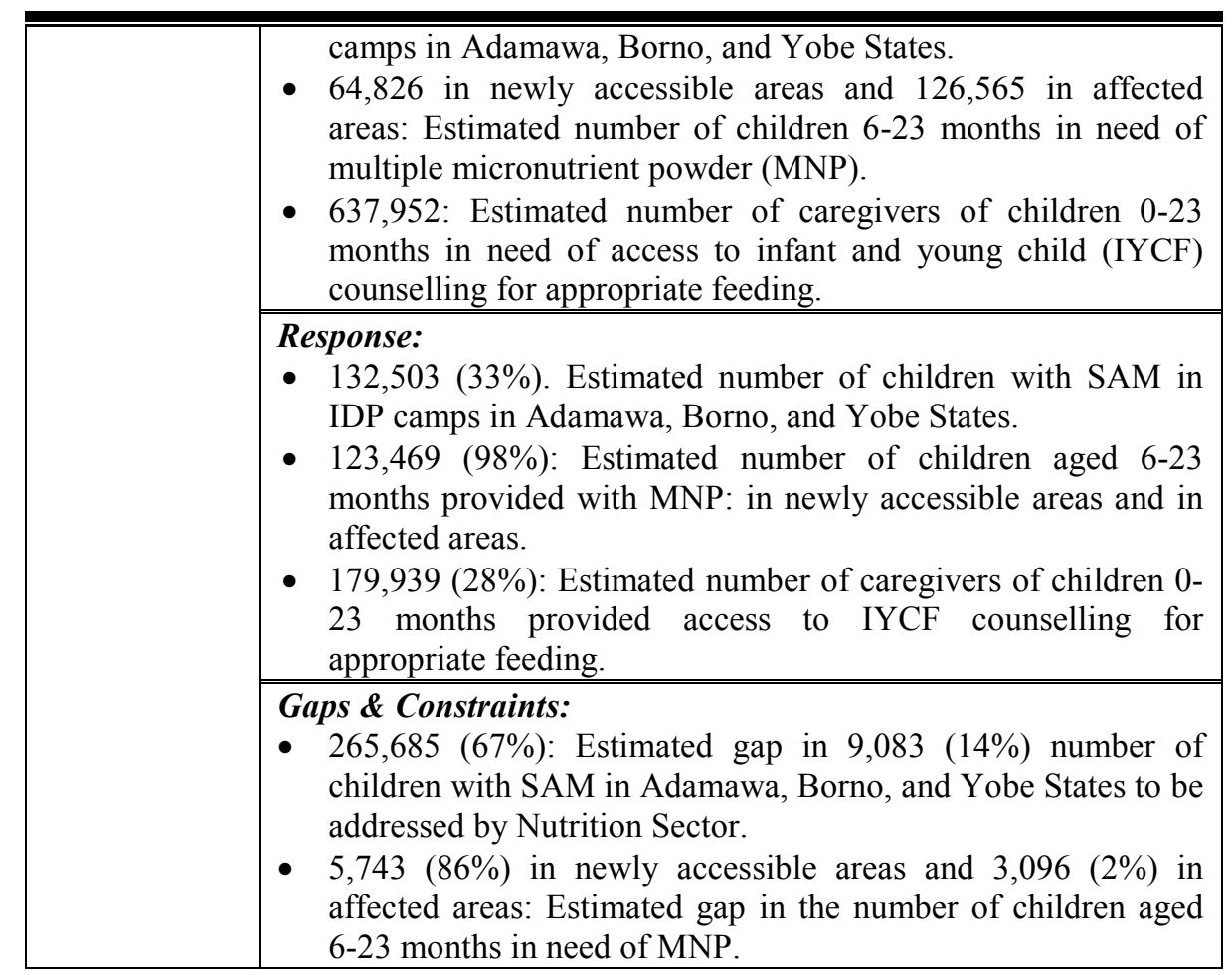

Source: United Nations Office for the Coordination of Humanitarian Affairs (2016)

\section{Health Security Challenges among Vulnerable IDPs}

Women and children constitute over $70 \%$ of internally displaced populations, and they experience a wide range of health risks (Getanda, Papadopoulos \& Evans, 2015). They are extremely vulnerable to physical and mental health problems, and they also have unique health needs (Mooney, 2005). Several studies have also reported that women and girls were victims of physical and sexual violence in IDP camps (Stark, Roberts, Wheaton, Acham, Boothby \& Ager, 2010; Vu, Adam, Wirtz, Pham, Rubenstein, Glass, 2014). Women are at higher risk of unwanted pregnancies, unsafe abortions, maternal morbidity and mortality. The negative impacts of sexual violence are significant and long term. These may include physical injuries, sexually transmitted infections including HIV, unwanted pregnancies and mental health effects (Austin, Guy, Lee-Jones, McGinn, Schlecht, 2007).

Similarly, epidemics of cholera, yellow fever and recently discovered hepatitis E have been reported in IDP and refugee camps across Africa (Nicole, 2015). Moreover, IDPs, particularly those affected by conflict commonly report psychological reactions are post-traumatic stress disorders (PTSDs) in reaction to violence and depression as a reaction to loss (Getanda, Papadopoulos \& Evans, 2015). Other types of mental health problems which have been reported are panic attacks and anxiety disorders (Saxon, Makhashvili, Chikovani, Seguin, McKee \& Patel, 2016). These behaviours are 
linked to an increased burden of non-communicable diseases such as hypertension, chronic obstructive pulmonary disease and cancers (Roberts, Patel \& McKee, 2012).

Health care services remain inadequate in North-eastern Nigeria, particularly in Borno, where Boko Haram insurgents had destroyed at least 75 health facilities as of May, as reported by the UN. Out of Borno's 27 LGAs, the report has it that only 13 have access to health care facilities. In response, the UN Health Sector had assisted in the construction of primary health care facilities for 17,000 new IDPs in Borno and Yobe as of late May.

As of early June, the GoN and UNICEF had provided integrated primary health care services to approximately 139,800 people-including nearly 69,300 children - in Adamawa, Borno, and Yobe. Services include deworming, HIV testing and counselling, measles and polio immunizations, malnutrition screening, and the distribution of Vitamin A supplements. IDP camps in northeastern Nigeria do not have functional latrines and adequate hygiene workers. In response, the GoN and UNICEF have provided 10,000 IDPs in Adamawa with access to improved sanitation facilities. The GoN and UNICEF have also distributed buckets, jerry cans, and soap to 3,600 residents of an IDP camp in Yobe's Damaturu town to help facilitate improved hygiene.

In partnership with the GoN, UNICEF has provided more than 78,000 conflict-affected people in North-eastern Nigeria with access to safe drinking water through the construction and rehabilitation of water access points. GoN and UNICEF are also steering water purification and monitoring the quality of water storage tanks in seven camps in Borno, which serve approximately 60,800 IDPs. In addition, UNICEF has provided training on safe hygiene practices to more than 85,000 people in northeastern Nigeria.

According to OCHA (2014), health was commonly cited among the top three needs of the displaced population. Adimula (2014) reported the case of about 80 pregnant women in Malkohi IDPs camp in Yola. One could imagine the reproductive health issues these women would face as a result of deliveries without trained birth attendants. Poor nutrition, poor sanitation, and communicable disease compromise the state of women's health. Lack of reproductive health services, including treatment for sexually transmitted diseases, put displaced women at higher risk of maternal mortality.

In certain cultures, women do not seek health services from a male practitioner. This also poses more health challenges to displaced women who may not have access to female health practitioners. Displaced persons are faced with health challenges because of lack of access to health care services and children usually suffer the most from inadequate health care. On the health challenges faced by IDPs in north-east, IDMC (2014) stated thus:

'IDPs and host communities in the north-east have only limited access to safe drinking water and adequate sanitation, leading to a decline in health and hygiene among both IDPs and their host communities. Public latrines in informal camp-like settings such 
as schools are often non-existent or unusable. Defecation and the disposal of children's waste in the open are common, particularly in urban or densely populated host communities. Open defecation raises health, security and dignity issues, particularly for women and girls, and creates tension with host communities. The contamination of water sources has contributed to cholera outbreaks in a number of displacement sites in Biu, Borno state'.

The Premium Times News and Guardian Newspaper reported that children were the victims of all the 450 deaths caused by malnutrition recorded in 28 Borno State IDPs camps in 2015. According to NEMA's executive director: $\mathrm{Mr}$ Sule Mele, these children were between age one and five and 209,577 children were screened for various illnesses, including malnutrition, malaria, diarrhoea and vomiting. He said, about 6,444 severe cases of malnutrition were recorded in the camps, 25,511 have mild to moderate symptoms, while 177,622 among them were not malnourished (Adimula, 2016). Displaced children also suffer stunted growth due to extended poor nutrition. The major health as well as water hygiene needs, response towards these needs and the gaps and limiting factors are presented in table 5 .

\section{Table 5: Health Security and Water Sanitation Challenges in IDP Camps}

\begin{tabular}{|l|l|}
\hline HEALTH & Needs: \\
- Majority of the IDPs need health assistance. \\
- The scale and coverage of health services in conflict affected \\
states in the northeast remains below minimum standards. \\
- Malaria remains the main cause of death. In Borno State over 50 \\
per cent of deaths are linked to malaria; in Adamawa State, \\
malaria, diarrhoea and chest infections remain the most prevalent \\
diseases in the camps.
\end{tabular}




\begin{tabular}{|c|c|}
\hline & aged six months to 15 years remains planned for early January. \\
\hline & $\begin{array}{l}\text { Gaps \& Constraints: } \\
\text { - As many as } 334 \text { health facilities have been burned, damaged or } \\
\text { closed; and functioning health facilities need medical equipment } \\
\text { and supplies. } \\
\text { - Insufficient number of skilled and appropriately trained health } \\
\text { staff. } \\
\text { - The number of health implementing partners is very limited to } \\
\text { respond to the increasing numbers of people in need; } \\
\text { humanitarian assistance in hard-to-reach areas remains largely } \\
\text { insufficient. } \\
\text { - } 14 \text { per cent of children aged between } 5 \text { and } 15 \text { risks dying of } \\
\text { malaria by the end of the year, because of an acute lack of access } \\
\text { to anti-malarial drugs. } \\
\text { - The poor state of water and sanitation infrastructures remain } \\
\text { among the main challenges affecting the health delivery system. } \\
\text { - } 87 \% \text { is the unmet funding requirements in the HRP } 2016 \text {. }\end{array}$ \\
\hline \multirow[t]{3}{*}{$\begin{array}{l}\text { WATER } \\
\text { SANITATION } \\
\text { HYGIENE }\end{array}$} & $\begin{array}{l}\text { Needs: } \\
\text { - Some } 3.65 \text { million people need WASH assistance (potable } \\
\text { water, sanitation, hygiene). } \\
\text { - Water provision remains critically low in some of the conflict- } \\
\text { affected areas; in Monguno only } 15 \text { per cent of the } 80,000 \text { IDPs } \\
\text { have access to water; within Borno State, the provision of } \\
\text { WASH services is uneven due to access constraints. } \\
\text { - For } 875,000 \text { IDPs in host communities in Maiduguri, only } 23 \\
\text { per cent of the water needs and nine per cent of the sanitation } \\
\text { needs are covered. } \\
\text { - Intensified fighting in northern areas are creating new } \\
\text { population displacements; recent reports have a figure of up to } \\
17,000 \text { for Nganzai LGA (approx. 5,000 were already there), } \\
\text { which in most of cases have no access or insufficient access to } \\
\text { WASH services. }\end{array}$ \\
\hline & $\begin{array}{l}\text { Response: } \\
\text { - Over } 1.1 \text { million people could access safe and clean water. } \\
\text { - Over } 7,100 \text { new emergency latrines for over } 1.4 \text { million people } \\
\text { established. } \\
\text { - Since the beginning of } 2016 \text {, some } 413 \text { boreholes were built and } \\
\text { over } 750 \text { rehabilitated. } \\
\text { - Close to } 1 \text { million people received hygiene messages through } \\
\text { campaigns, house-to-house visits, and the distribution of } \\
\text { hygiene kits. }\end{array}$ \\
\hline & $\begin{array}{l}\text { Gaps \& Constraints: } \\
\text { - Funding is still a major constraint: less than } 15 \% \text { of the } \\
\text { requested } \$ 48 \text { million have been met so far. } \\
\text { - No WASH actor presence or previous WASH activities in } \\
\text { Nganzai LGA results in a further challenging response for } \\
\text { provision of humanitarian assistance here. } \\
\text { - New coordination initiatives put forward by the CCCM/Shelter }\end{array}$ \\
\hline
\end{tabular}




\begin{tabular}{|l|l|}
\hline Sector for improved humanitarian assistance in Muna Garage \\
presents an opportunity to WASH agencies to aid in this \\
growing camp. However, the lack of physical space is \\
conditioning the sanitation response in favour of solutions that \\
require less space. This is a plus in terms of ownership from the \\
IDPs' side, but poses a considerable potential risk for \\
environmental sanitation during next year's rainy season. \\
- In Adamawa State, close to 24,000 individuals both in host \\
communities and formal camps received assistance from the \\
WASH sector; NFIs distributed to some 19,000 people since \\
October.
\end{tabular}

Source: United Nations Office for the Coordination of Humanitarian Affairs (2016)

\section{International Strategies for the Protection of IDPs}

The Fourth World Conference on Women in Beijing (1995) brought the topic of women and conflict to international attention. In 1999, UNICEF and the Women's Commission for Refugee Women and Children organized an Expert Meeting on Gender Dimensions of Internal Displacement to develop strategies to address the gender issues during internal displacement. They concentrated on some areas for action such as the safeguarding of women against rape, abduction, forced marriage, slavery, torture and murder (Gururaja, 2000).

Although the United Nations agencies attempt to help displaced women cope by providing the necessities such as food, security and support, most women continue to face discrimination in the settlement camps. For example, in one Burundi camp in 1994, there were only 25 men out of a camp populated with several thousand women, when the UN representative asked to consult with some leaders of the camp to discuss the problems faced by its residents and only men appeared. Gender-based problems also arise when supplies are distributed only through men. The women were in most instances forced to trade their bodies to get their rations. Displaced women are still exploited in exchange for food, shelter and other items including physical protection (UN, 1995).

Article 66 of the African Charter on Human and Peoples' Rights provides for special agreements to supplement the provisions of the African Charter. The Assembly of the Heads of State and Government of the Organization of African Unity (OAU) meeting in its Thirty-First Ordinary Session in Addis Ababa, Ethiopia, June 1995, endorsed by resolution AHG/Res.240 (XXXI) the recommendation of the African Commission on Human and Peoples' Rights to establish a Protocol on the Rights of Women in Africa during armed conflict. This was further adopted by the 2nd Ordinary Session of the Assembly of the African Union in Maputo, 11 July 2003 as follows:

Article 11: Protection of Women in Armed Conflicts

Article 11 in line with global protection of women in conflict situations gave the following guidelines for the protections of women IDPs in war prone region; 
- States Parties undertake to respect and ensure respect for the rules of international humanitarian law applicable in armed conflict situations, which affect the population, particularly women.

- States Parties shall, in accordance with the obligations incumbent upon them under the international humanitarian law, protect civilians including women, irrespective of the population to which they belong, in the event of armed conflict.

- States Parties undertake to protect asylum-seeking women, refugees, returnees and internally displaced persons, against all forms of violence, rape and other forms of sexual exploitation, and to ensure that such acts are considered war crimes, genocide and/or crimes against humanity and that their perpetrators are brought to justice before a competent criminal jurisdiction.

- States Parties shall take all necessary measures to ensure that no child, especially girls under 18 years of age, take a direct part in hostilities and that no child is recruited as a soldier.

To implement the international policies and declarations put in place, there are about sixteen international organizations that attempt to improve the situation of women in armed conflicts by peace keeping, peace negotiation, peace building, humanitarian relief aid, development assistance and international tribunals or courts. Some of those include: United Nations Security Council (SC); United Nations Department for Peace Keeping Operations (DPKO); United Nations Development Programme (UNDP); United Nations High Commission for refugees (UNHCR); World Food Programme (WFP); North Atlantic Treaty Organization (NATO); International Labour Organization (ILO); International Criminal Tribunal for the Former Yugoslavia (ICTY); International Committee of the Red Cross (ICRC); Organization for Security and Cooperation in Europe (OSCE); Council of Europe (COE); Gender Task Force (GTF): of the stability Pact of South eastern Europe; International Criminal tribunal for Rwanda (ICTR); International Criminal Court (ICC); Netherlands Ministry of Foreign Affairs (MOFA) and Netherlands Ministry of Defence (MoD) European Commission (EC, 2005; UNESCO, 2004).

\section{Theoretical Discussion of Findings}

The findings of this study are twofold. First, regarding food security and nutrition, the situation faced by IDPs is increasingly distressing. As a result of several factors including the inaccessibility of some areas within these regions, destruction of farmlands and insecurity of trade routes, there is a major problem of food security in the IDP camps. In instances where food is available, it still remains below the standard of the required dietary standards. This presents a major challenge for children who need all essential nutrients for growth as well as for women, especially nursing mothers with special health needs. 
Second, in the area of health security and water sanitation, the study revealed that IDPs are in dire need of health assistance. Several medical facilities have been burnt down and medical personnel have gradually relocated for fear of being hurt. The worst hit remain the children as well as the women who are exposed to malaria, cholera and other diseases. A major hindrance to the security challenges facing IDPs as observed from the findings is the problem of funding. As disclosed by the UNHCR regional update (2017) only a total of USD 1.9million has been funded out of USD 170.2 million required, representing only $1 \%$ of the funding needs.

Thus, within the purview of the human security approach and the feminist theory, the women and children have double concerns. Not only have they been displaced and forced to seek refuge in harsh environments, their helpless condition makes survival very difficult. Therefore, since the human security approach focuses on what the vulnerable population need to feel safe and secure specifically food security and access to health while the feminist theory examines the situation from the lenses of women and children who are affected by displacement as the situation intensifies, the findings of this study are embedded in these two theories. The major finding of this study can simply be stated thus- the adverse food insecurity and health challenges facing the entire population of IDPs has a worsened effect on women and children as a result of their vulnerable position.

\section{Conclusion}

The deplorable food and health challenges faced by internally displaced persons in Nigeria has caught the attention of the world with almost all major world developmental agencies concentrating on Nigeria. The situation in the Northeast and North central due to the Boko Haram insurgency and Fulani herders/farmers conflict has gotten to its peak. Furthermore, the group that seems to be the most vulnerable as highlighted by this study are women and children who face untold human security challenges. However, for this study, the emanating food and health security challenges as faced by women and children in the country was examined. This study revealed that the food crises situation as witnessed by the vulnerable population has reached a stressed and emergency state. Also, this study reiterated that if urgent interventions are not put in place to alleviate the situation as experienced especially in the Northeast, the food security situation will deteriorate completely.

Also, this study revealed that women and children are faced with several health challenges. For children, the study showed that most common health problems as experienced by children include; malnutrition, lack of calories, cholera, and other child borne diseases. The women on the other hand are exposed to health insecurities such as; physical and mental health problems, physical and sexual violence, unwanted pregnancies, unsafe abortions, maternal morbidity and mortality, HIV/AIDS etc. 


\section{Recommendations}

Based on the findings from this study, the following recommendations have been made. First, more funding is urgently needed to implement essential interventions in especially in newly liberated areas from the grip of Boko Haram. As the latest funding overview of the Humanitarian Response plan reports shows that the health sector is currently $13 \%$ funded, which is far below the level required to conduct the scale up required to address unmet health needs amongst internally displaced populations.

Second, some of the human security challenges as experienced by vulnerable groups are man-made. Thus, even though government, NGOs and other civic society organizations have made adequate provisions for food and health resources, IDP camp coordinators and workers purposefully divert these resources for personal use, or sell them, or demand for sex especially from young girls in exchange for these items. Therefore, there is the need for proper coordination among NGOs and other humanitarian bodies to ensure items provided for IDPs (especially women and children) are not diverted. More so, those found to be culprits of such despicable acts should fully face the weight of the law.

Furthermore, the government of Nigeria has always been a reactive one instead of being proactive. They get all the warning signs of violence, invasions from herdsmen, flood alerts etc, yet they treat such warnings with kid gloves. Hence, such attitude needs to be addressed. On this note, government should erect a fully equipped designated area for IDPs in all states, as this will reduce the rush IDPs often face which eventually create security challenges in camps.

Additionally, there is barely any provision made for national emergencies in our budgetary allocations. We therefore tend to wait until an emergency erupts before we start making frantic efforts to manage the situation. On this note, it is imperative that national and state governments make adequate budgetary allocation for displacement in Nigeria which should be given separate attention from all other allocations for disaster and/or emergency situations.

Again, given the fragility and vulnerability of women, children and the aged, special attention must be paid to this group of persons by ensuring that they are the first to receive relief items before proceeding to distribute to other groups of persons as they cannot withstand the huddle of hustling for relief materials.

Finally, there is the need for the Nigerian government to triple its effort at bringing the root causes of displacement to a halt. In other words, the Boko Haram insurgency must be completely decimated and obliterated, the Fulani/herdsmen clashes must be resolved amicably, and for those whose primary objectives are to maim and kill, the government must ensure that they are viciously dealt with. 


\section{References}

ActionAid (2016) On the frontline: Catalyzing women's leadership in humanitarian action. ActionAid.

Aday, L.A. (1991) Who are the vulnerable? In: At Risk in America: The Health and Health Care Needs of Vulnerable Populations in the United States. 2nd ed. San Francisco, Calif: Jossey-Bass; 1-15.

Adimula, B. (2016) Opinion: The plight of women and children in Nigeria's IDP camps. Retrieved from http://ynaija.com/idp-women-children/.

Aldis W. (2008) Health security as a public health concept: a critical analysis. Health Policy and Planning, 23(6): 369-375.

Austin, J., Guy, S., Lee-Jones, L., McGinn, T., Schkecht, J. (2008) Reproductive health: A right for refugees and internally displaced persons. Reproductive Health Matters, 16(31): 10-21.

Ayinmoro, D.A. \& Uzobo, E. (in press) 'Forced Migration and Human Security Challenges in Nigeria' In the Nigerian Anthropological and Sociological Practitioners Association (NASA) Book: Society and Security.

Baldwin D. (1997) The concept of security. Review of International Studies, 23: $12-18$.

Clay, E. (2002) Food Security: Concept and Measurement. Paper for FAO expert consultation on trade and food security: Conceptualising the linkages. Rome.

Durosaro, I. and Ajiboye, S. (2011) Problems and Coping Strategies of Internally Displaced Adolescents in Jos Metropolis, Nigeria. International Journal of Humanities and Social Science, 1(20): 256-262.

Famine Early Warning System Network (2000) Tanzania food security update.

Flores, D.J. \& Zydor, S. (2014) Vulnerable Populations and Beyond. Office of the Human Research Protection Program.

Food and Agriculture Organization of the United Nations (1983) World Food Security: A Reappraisal of the Concepts and Approaches. Director General's Report. Rome.

Food and Agriculture Organization of the United Nations (2002) Measurement and Assessment of Food Deprivation and Underdevelopment. International Scientific Symposium. Rome.

Food and Agriculture Organization of the United Nations (2016) Cadre Harmonisé for Identifying Risk Areas and Vulnerable Populations in Sixteen (16) States of Nigeria: Food and Agriculture Organization of the United Nations.

Getanda, E.M., Papadoupoulous, C. \& Evans, H. (2015) The mental health, quality of life and life satisfaction of internally displaced persons living in Nakuru Country, Kenya. Retrieved from https//www.ncbi.nlm.nih.gov/pmc/articles/PMC4527222/ 28th September, 2017.

Guraja, S. (2000) Gender Dimensions of displacement. Forced Migration Review, 9: 13-16). 
Internal Displacement Monitoring Centre (2016) Global Report on Internal Displacement. IDMC: Grid

Internal Displacement Monitoring Centre (2014) "Nigerian authorities published official figures for the first time this year, and put the number of IDPs in the country at 3.3 million". Retrieved from www.internaldisplacement.org/.../Nigeria/figures-analysis on 20/05/16.

International Organization for Migration (2016) Internally Displaced Population Falls in Mali. Press Release https://www.iom.int/news/internally-displaced-population-falls-mali.

Kampala Convention (2009) African Union Convention for the Protection and Assistance of Internally Displaced Persons in Africa. African Union Economic, Social and Cultural Council (ECOSOCC), Secretariat.

Kett, M. (2005) ABC of conflict and disaster- Displaced populations and long term humanitarian assistance. British Medical Journal, 331(7508): 98-100.

Lancet Editorial (2007) WHO fails to address health security. The Lancet, 370 : 714.

Maxwell, S. \& Smith, M. (1992) Household food security: A conceptual review. In S. Maxwell and T. Frankenberger (Eds.). Household food security: Concepts, indicators and measurements: A technical review. New York, NY, USA and Rome, UNICEF and IFAD.

Mooney, E. (2005) The concept of internal displacement and case for internally displaced persons as a category of concern. Refugee Survey Quarterly, 24(3): 9-26.

Moser, C. (1993) Gender planning and development: Theory, practice and training. London: Routledge.

Nicole, W. (2014) The WASH approach: Fighting waterborne diseases in emergency situations. Environ Health Perspect, 2015(123): A6-15.

Norwegian Refugee Council (2016) Norwegian Refugee Council Nigeria-Fact Sheet.

Owoaje, E.T., Uchendu, O.C., Ajayi, T.O., Cadmus, E.O. (2016) A review of health problems of the internally displaced persons in Africa. Niger Postgrad Med J, 23: 161-171.

Robert Wood Johnson Foundation. A portrait of the chronically ill in America, (2001) Available at: http://www. rwjf.org/files/publications/other/Chronic Illness Chartbook 2001.pdf. Accessed August 2, 2006.

Roberts, B., Patel, P. \& McKee, M. (2012) Non-communicable diseases and post conflict countries. Bulletin of the World Health Organization. 90(1): $2-2 \mathrm{~A}$

Saxon, L., Makhashvili, N., Chikovani, I., Seuin, M., McKee, M., Patel, V. (2016) Coping strategies and mental health outcomes of conflict affected persons in the Republic of Georgia. United Kingdom: Cambridge University Press.

Siriwardhana, C. \& Wickramage, K. (2014) Conflict, forced displacement and health in Sri Lanka: A review of the research landscape. Retrieved 28th 
September, $2017 \mathrm{https} / /$ conflictandhealth.biomedcentral.com/articles/10$.1186 / 1752-8-22$.

Stark, L., Roberts, L., Wheaton, W., Acham, A., Boothby, N. \& Ager, A. (2010) Measuring violence against women amidst war and displacement in northern Uganda using the 'neighbourhood method'. J Epidemiol Community Health, 64(12): 1056-1061.

Tadjbakhsh, S. (2007) Human Security: Concepts and Implications. London: Routledge.

United Nations (1975) Report of the World Food Conference, Rome. Development Biblography 8, Brighton, Institute of Development.

United Nations Development Programme (1994) Human Development Report. Oxford: Oxford University Press.

United Nations Development Programme (1994) Human Development Report: Human Rights and Human Development, New York: United Nations

United Nations Development Programme, (2000), Human Development Report 2000: Human Rights and Human Development, New York: United Nations

United Nations High Commissioner for Refugees (2017) Nigeria Situation. UNHCR Regional Update

United Nations International Children's Educational Fund (1998) The State of the World's Children. Oxford: Oxford University Press.

United Nations Office for the Coordination of Humanitarian Affairs (2016) North-east Nigerian: Humanitarian emergency-Situation report No. 1.

United Nations Refugee Agency (2016) Global trends: Forced displacement in 2016.

Vu, A., Adam, A., Wirtz, A., Pham, K., Rubenstein, L., Glass, N., Beyrer, C. \& Singh, S. (2014) The prevalence of sexual violence among female refugees in complex humanitarian emergencies: A systematic review and metaanalysis. Retrieved from https//www.ncbi.nlm.nih.gov/-pmc/articles/PMC4012695/ 28th September, 2017.

World Bank (1986) Poverty and hunger: Issues and options for food security in developing countries. Washington DC.

World Health Organization (2007) World Health Report 2007: a safer future: global public health security in the 21 st century. Geneva: World Health Organization. 